\title{
Case Study 2: Designing PLE for Higher Education
}

\author{
Denis Gillet and $\mathrm{Na} \mathbf{~ L i}$
}

\begin{abstract}
In this chapter, the concept of Personal Learning Environment is first refined taken into account recent advances and the experience gathered in a European research project dedicated to responsive open learning environments. A prototypal implementation of a Web 2.0 platform enabling the construction, the sharing, and the repurposing of personal learning environments is then introduced. Participatory design and validation activities carried out in the framework of higher education test beds aiming at understanding the benefits of personal learning environments in academic institutions are presented. Finally, the broaden application framework for the deployment and the adoption of open user-centric environments for learning and knowledge management is tackled with perspectives in terms of supporting inquiry learning at school with online laboratories, implementing connectivist massive open online courses or enabling agile information systems for nongovernmental organizations.
\end{abstract}

Keywords Personal Learning Environment (PLE) • Informal learning • Higher education • Social Learning • Web 2.0

\section{Introduction}

\section{Trends}

Higher education is transforming under both top-down and bottom-up pressure. On one hand, national policies and international practices are pushing higher education institutions to reinforce their branding to attract more students to prime the researchers pump and to trigger more citations to boost rankings. On the other hand, students currently enrolled in higher education study programs are born with the Internet and have grown as teenagers with ubiquitous access to online resources (free or considered as such), peers, and communities, thanks to flagship search engines and social media platforms. A previous study (Vassileva 2008) has pointed

D. Gillet $(\square) \cdot N$. Li

Ecole Polytechnique Fédérale de Lausanne (EPFL), Lausanne CH-1015, Switzerland e-mail: denis.gillet@epfl.ch 
out that, today's teenagers are used to learn in context, in response to a perceived demand, or to solve a particular problem. They search the Internet to find articles, videos, or any related materials, as well as scouting through their social networks to find a person who may be able to help. These learning experiences are mostly "solution-driven," rather than "learning on principle."

As a consequence, the school- and course-centric closed learning management systems (LMS) do not fulfill and match anymore the institutions and students' expectations and practices. They do not provide the necessary international visibility for the institutions to be recognized as excellence teaching centers and they do not provide students with the open and persistent free access to resources and peers they are used to. The activity- and student-centric model of personal learning environments (PLE) better supports the opportunistic and agile scheme required by students to interact with resources, experts, and peers for both social and educational purposes. The LMS rather enforce the old teaching model focusing mainly on top-down content delivery through lectures, slides, course notes, and fully packed exercise sessions.

The current trend is to equip institutions, teachers, and students with skills and technologies to combine local institutional resources with global open content from the cloud, as well as to rely on internal and external support provided by peers or experts.

Students have always exploited resources from libraries and relied on peer interaction for learning outside the formal institutional settings and activities. However, with the current ubiquitous access to information and communication technologies, such informal learning activities and modalities are taking a more important place in the higher education landscape (Gillet 2010).

Activities carried out in the $\operatorname{ROLE}^{1}$ project have contributed to investigate a pedagogical framework to strengthen self-directed and informal learning, as well as a technical framework to benefit from Web 2.0 PLE. One should also highlight that in the informal setting considered in this chapter, the boundary between learning and knowledge management (KM) is disappearing (Fig. 1).

In the next paragraphs, we provide insights on the current definition of PLE and discuss alternative design and implementation approaches. Then, in section "Dedicated PLE Platform," we present the social media platform designed in the PALETTE (El Helou et al. 2009) and the ROLE (Gillet et al. 2010) projects to enable interaction in online learning communities and agile construction and exploitation of PLE by teachers and students. In section "Higher Education Test beds," test beds set to validate the benefits of such platforms in higher education are presented together with evaluation results. In the ROLE project, these test beds also played an important role for the participatory design and the social requirement engineering processes. Finally, in section "Conclusions and Perspectives," conclusions are drawn and perspectives are provided in terms of supporting inquiry learning at school with online laboratories, implementing

\footnotetext{
${ }^{1}$ http://www.role-project.eu
} 
Fig. 1 Trends supporting the emergence of personal learning environments in higher education

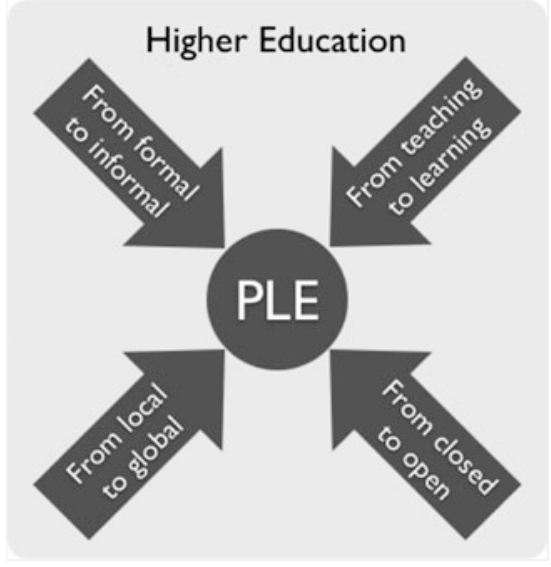

connectivist massive open online courses (cMOOCs) or enabling agile information systems for nongovernmental organizations (NGO).

\section{Definition of a PLE}

The concept of PLE is not new. According to Wikipedia, ${ }^{2}$ it was first coined in the 1970s. It was however rediscovered and consolidated with the emergence of the social Web (Web 2.0) that enabled users to take control of their online resources and interact freely with peers worldwide. Nowadays, conferences series such as the PLE Conference ${ }^{3}$ are fully dedicated to discuss issues and investigations related to PLE.

Initially, definitions of PLE were enforcing the combination of the online and physical resources to define the learning settings. As example, both the computer applications and the physical books the students may use on a desk at home to carry out a given activity can be considered as part of the corresponding personal learning environment. The same could be said for peers sitting around a table in a cafeteria and discussing or completing homework assignments. However, physical modalities and the associated offline actions are difficult to identify and to track within supporting online platforms; the tendency is then to ignore them or to consider them as embodied in the user model. Other definitions were mainly focusing on the concept of mashup of Web applications (apps), which happened to be too restrictive (Wild et al. 2008).

The current conceptualization of a PLE is rather corresponding to an opportunistic aggregation of online content, information, services, and people for a given

\footnotetext{
${ }^{2}$ http://en.wikipedia.org/wiki/History_of_personal_learning_environments

${ }^{3}$ http://pleconf.org
} 
Fig. 2 The PLE as an aggregation of information, content, services, and people

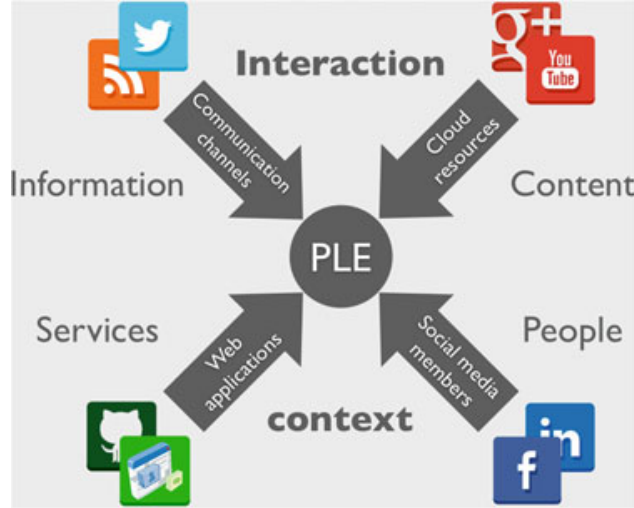

activity. The variety of physical interfaces enabling the access and the interaction with the mentioned entities is also evolving and is currently integrating not only desktop and laptop computers, but also mobile devices such as smart phones and tablets. Data gathered or published by online smart devices can also be considered as resources or channels. As a consequence, we can define a PLE as (Fig. 2) (Gillet 2013)

a shared online opportunistic and possibly ephemeral aggregation of communication channels, cloud resources, Web applications, and communities or peers (directly or through social media memberships), assembled in an agile way to define an interaction context for a given learning or knowledge management purpose, and accessed through interactive devices (computers, tablets, smart phones, ...).

In this definition, communication channels correspond to live discussion streams or notifications usually made of short text messages or links. Content is referring to multimedia resources that exhibit some persistence. Loosely-coupled distributed services and online tools are accessed using Web applications.

It is important to enforce that any digital ecosystem can be considered as a PLE if it has been repurposed for learning and knowledge management. It is more the intention of use than the design itself that defines the nature of the environment (Charlier et al. 2010). Obviously, the construction of the environment is part of the learning activities and is an important ingredient in the appropriation of the resources and the motivation to carry out the corresponding learning activity. As such, the PLE realm pushes further constructivism, by not only enforcing the definition of personal activities and resources by learners, but also by shaping the related interaction environments. As embedded in the PLE term, such environments are personal. They are however not individual as most of the time interaction with peers or experts is desired and supported. Finally, one should underline that each learning or knowledge management activity carried out by a user may rely on different tools and resources, and, as such may require the construction of a different PLE. This is the reason why PLE are often ephemeral, i.e., they may be abandoned once the activity is completed. It is also why their construction should be agile, i.e., they should be shaped to each context and purpose. 
The above definition clearly shows the importance of the agile construction of the PLE by the users themselves. Such a construction requires quite high IT literacy and self-directed learning skills. The higher education framework is hence an interesting setting for validation of the PLE paradigm, as the acquisition of autonomy is one of the main educational objective and outcome. Section "Conclusions and Perspectives" will especially show that students and early-stage researchers enrolled in graduate studies programs form an interesting community to elicit PLE requirements and evaluate PLE benefits.

The ROLE project attempted to provide guidance for the design of self-directed activities and environments to students without the necessary level of autonomy, but had troubles to provide evidence that IT tools could help students with limited IT literacy to build IT environments on their own. For more autonomous students, the definition of personal learning objectives and the selection of the corresponding resources and services appeared to be generally carried out implicitly, requiring as such no specific technical support.

\section{Alternative Design and Implementation of PLE Platforms}

If one would stick on the PLE definition proposed in the previous paragraph, there should be neither design nor implementation of platforms enabling the construction of PLE. Any set of communication channels, cloud resources, Web apps, and people assembled by a user would become a PLE. As a matter of fact, most of the students in higher education build their own learning environments without identifying them as a PLE and even without noticing that they are actually building learning environments. A simple set of URLs, a LinkedIn ${ }^{4}$ or a WhatsApp ${ }^{5}$ group dedicated to a given topic studied could be considered as a PLE.

As the concept of a free ecosystem assembled by a user fits very well with the definition of PLE, it makes it difficult to induce changes in the way higher education institutions shared and exploit knowledge and support students in both their formal and informal learning activities. It also makes difficult the development of IT literacy and autonomy for bachelor students in the usage of the social media platforms and channels for educational purposes. Social media platforms and channels are mainly considered as social interaction and entertainment tools. Last but not least, the current digital ecosystem solutions do not facilitate the storage, the sharing, and the repurposing of personal aggregations related to the study of given topics or the completion of specific activities. As a consequence, teachers and students have the tendency to continuously reinvent the wheel in putting together their learning environments.

\footnotetext{
${ }^{4}$ https://www.linkedin.com

${ }^{5}$ http://www.whatsapp.com
} 
Following the above comments, it is still beneficial to adapt current LMS to enable a more flexible exploitation and enrichment of the learning resources and contexts by the students, as well as to provide alternative platforms to enable the construction and the sharing of PLE by the users for the users. The next section describes the Web 2.0 PLE platform designed and developed in the framework of successive technology enhanced learning research projects, especially in ROLE, to support the construction of PLE, their sharing and their repurposing.

\section{Dedicated PLE Platform}

\section{Design Objectives and Models}

As stated before, a PLE is an aggregation of dedicated channels, resources, apps, and people by a user, i.e., typically a teacher or a learner, for a specific learning or knowledge management purpose. So, any platform supporting the construction of PLE should support the aggregation of the mentioned entities and their hosting. For the sake of symmetry in the way we treat the various entities being part of a PLE, we talk about the aggregation of people, which in fact means the ability of sharing the PLE with peers or experts and the possibility of repurposing it for their own or collaborative usage. When dealing with entities gathered from the cloud, due to their plethora, search and recommendation features are required. Finally, in an open framework where users may prefer different platforms to exploit their own PLE or the ones shared by others, import and export features in open Web standards are important (Fig. 3).

The concept of PLE being abstract, for design and implementation purpose it should be materialized as an online context dedicated to support a selected individual or shared activity. As a consequence, we coined the concept of online spaces as

Fig. 3 Required features for PLE platforms enabling the agile construction and exploitation of personal learning environments

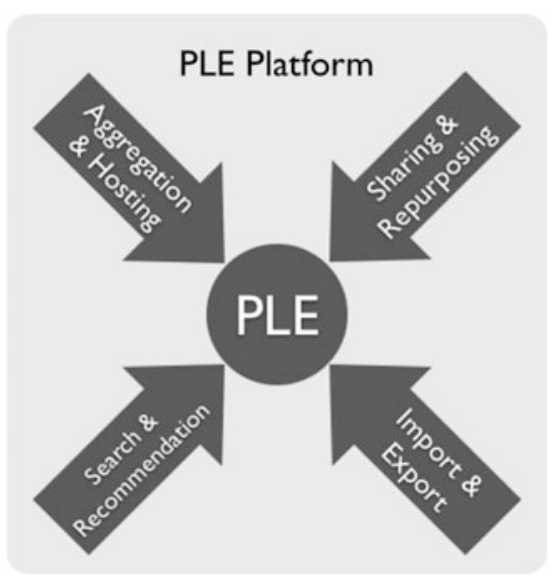


the personal online places in which communication channels, cloud resources, Web apps and people are aggregated to support specific individual or shared activities.

This space concept has first been introduced in Gillet et al. (2008), then formalized in El Helou et al. (2010) as the 3A model, and finally standardized in Bogdanov et al. (2011) as an OpenSocial ${ }^{6}$ space specification. Hence, in the rest of this chapter, the notion of PLE, space and learning context are considered as equivalent. Obviously, a particular case of a share activity is an individual activity and a specific case of cloud resource is an internal resource (belonging to an institutional or an enterprise cloud).

The agile creation by aggregation and the repurposing of a PLE being by essence a user-centric self-directed activity, the user should be able to set easily privacy settings and to assign specific roles and rights to the various people he or she is sharing the PLE with, i.e., the people he or she is carrying out the activity with. Such people are considered as the members of the shared online space. The lack of a fine control in the privacy settings and in the selection of people for specific activities is one of the reasons why LMS and flagship social media platforms are not very convenient to support the creation of PLE. The other reason seems that users do not want to mix their social and professional or educational networks online, and do not perceive a connection between their online activities and learning in classrooms (Greenhow and Robelia 2009).

The notion of open educational resources (OER) is embedded and even extended in PLE. In effect, in addition to promoting the sharing of resources like multimedia documents, in the PLE framework we promote the sharing of Web apps offering dedicated services only required for specific activities and the sharing of the PLE themselves. In (Gillet and Bogdanov 2013), it is shown how a PLE instantiated as an OpenSocial space can be openly or privately shared as a meta-widget. OpenSocial apps (widgets, gadgets or meta-widgets) are in fact a combination of $\mathrm{xml}$ and javascripts. They can be compared to readable digital artifacts and shared using Creative Commons ${ }^{7}$ licenses. Such licenses are more suitable for the model of applications as a service (AaaS) relying on distributed infrastructures than the old open source licensing schemes working only for software that can be delivered on a memory stick as a standalone package.

\section{Prototypal Implementation}

Taking into account the specifications for a PLE platform stated in section "Dedicated PLE Platform," the Graasp ${ }^{8}$ platform has been designed and implemented following an agile development methodology combined with participatory design

\footnotetext{
${ }^{6}$ http://opensocial.org

${ }^{7} \mathrm{http}: / /$ creativecommons.org

${ }^{8}$ http://graasp.epfl.ch
} 
and validation in test beds, including the ones described in section "Higher Education Test beds." The elicited requirements could be summarized as the following design objectives for the platform that should:

- Enable the creation of PLE without the intervention of system managers.

- Be free of rigid structures and contexts (such as a course structure with specific types of activities and resources).

- Enable opportunistic and focused activities.

- Enable the aggregation of cloud resources.

- Enable agile management of resources in contexts.

- Enable the fine control of roles and rights in contexts.

- Provide open search and meaningful recommendation of resources, apps, and people.

- Rely on open Web standards similar to the ones used by social media and knowledge management platforms (avoiding carefully any specialized standard like the one dedicated only to learning).

The core Graasp feature is to enable the creation and enforce the exploitation of dedicated online spaces as activity contexts (PLE). These spaces are defined, configured, shared, and populated by users, for themselves and for the audience they choose. Graasp stands for grasping resources, apps, activity spaces, and people. As a matter of fact, any space can embed subspaces supporting subactivities. However, hierarchy is not enforced. Users may decide to create either a flat or a hierarchical space structure to support their various learning or knowledge management activities.

Graasp spaces can include members, resources, subspaces, and apps. In addition, each entity has its own description implemented as a wiki enabling collaborative edition, a dedicated discussion thread, tags, and personal or public ratings, enforcing in such a way contextual exploitation (see Fig. 10 in Chap. 8).

In Graasp, there are three audience levels. Spaces can be public, i.e., visible to everybody, closed, i.e., restricted to their members (but external people can request membership), or hidden, i.e., only accessible by invited members. There are also three possible roles for the members of a space. They can be owner, which means that they can add or remove resources, as well as invite members or revoke memberships. The owner role can be assigned to more than one member of a space, which is a unique Graasp feature that enables to pass responsibilities over when required. People can be contributors, which means that that can add resources and can create subspaces for which they have the full control of the participants. Finally, people can be viewers, which means they can access but not alter the content of a space. They can however post comments, which is an important part of the asynchronous interaction in shared online activities.

The agile aggregation of cloud resources is supported by an open source plugin architecture and implemented as a GraaspIt! bookmarklet which provides a one-click aggregation of external resources in the Graasp clipboard for further integration in spaces (see the Chap. 8 for more details). 


\section{Higher Education Test Beds}

Offering a PLE platform to teachers and students in a higher education setting is a way to provide them with more opportunities and facilities to exploit and repurpose individually or collaboratively learning resources gathered from various sources. For adoption, such platforms should bring a high added value compared to institutional solutions extensively deployed like LMS. If a teacher wishes to share the slides of one lecture with students enrolled in a class, using the institutional LMS is obviously the way to go. However, if the objective is to help the students to develop teamwork skills by completing autonomously a collaborative project involving not only classmates, but also alumni or external experts, a PLE platform is a better and more agile solution.

In this section, two test beds are described. First, the scenario and the evaluation of the exploitation of a PLE platform for teamwork activities as part of a bachelor course on Human Computer Interaction offered at Tongji University is presented. The design of social media platforms being part of the syllabus, the advantage of using a PLE platform in this case is twofold. It helps to illustrate the subject matter and it enables an easy management of the self-defined activities and the co-produced assets by the students themselves. Second, the support of interinstitutional training activities on Science 2.0 practices and solutions for doctoral students at the Swiss national level are detailed. Again, the benefits are twofold. The doctoral students discover how social media platforms can support their daily research activities and they also exploit the same platforms to exchange best networking and dissemination practices.

These two cases emphasis the fact that using PLE or social media platforms in higher education is simultaneously a will to help users in developing IT literacy and teamwork skills, as well as a way to empower them in their learning practices.

\section{Teamwork at the Bachelor Level}

To examine the acceptability of Graasp in terms of supporting teamwork in higher education, it was used as a collaborative platform in the Human Computer Interaction course offered at Tongji University in China during two consecutive years, i.e., in 2011 and 2012. Twenty-eight undergraduate students were enrolled in the course during the first year and 26 during the second.

In addition to attending traditional lecture sessions, the students had to complete a collaborative design project using Graasp as a support platform. Both years, eight participatory design teams of 3-4 students were freely formed. The students spent about $10 \mathrm{~h}$ to design the mockup of a social media application. They also delivered a short report and gave a final presentation to their classmates and experts.

After a short introduction to Graasp, students were encouraged to create their project spaces, share resources with each other, play different roles for the 
participatory design (manager, designer, user, developer), and work with different project-oriented apps (task assignments, mockup edition, ...). A survey was conducted aiming at evaluating the acceptability of the platform in sustaining collaborative learning. Results of the 2011 evaluation have been detailed by Li et al. (2012). The importance of privacy settings for shared spaces was confirmed by the fact that in $201150 \%$ of the spaces created were set to public, $47 \%$ closed and $3 \%$ hidden, and in 2012, $60 \%$ were set to public, $32 \%$ closed and $8 \%$ hidden. The students had also to pick five adjectives that closely matched their personal reactions to Graasp from a list of positive and negative words (Benedek and Miner 2002). A word cloud, showing the frequency of the selected adjectives is presented in Fig. 4 and Fig. 5 for year 2011 and 2012, respectively. The word clouds show that the personal control, the ubiquitous accessibility and the trust enforcement of the PLE platform are part of the core added value. Results also show that improvements were achieved through participatory design between the two evaluations as efficiency and ease-of-use increased.

Students' answers show that they do not have traditionally support platforms for teamwork, for which they mainly use instant messaging applications (100\% in 2011 and $59 \%$ in 2012) or email (64\% in 2011 and $38 \%$ in 2012) simultaneously or not. The introduction of Graasp was hence quite welcome. Students assessed that thanks to this platform they could accomplish their teamwork more effectively and that their motivation increased (only $10 \%$ disagree with these statements). The fact that they can easily share resources with teammates, freely organized them, and seamlessly aggregate content from different sources were the main useful features according to the students (Fig. 6).

This evaluation confirms that PLE platforms are useful for self-directed activities carried out by bachelor students and involving agile resources aggregation, roles assignment as well as right management.

Fig. 4 A word cloud based on frequency of selected adjectives in 2011

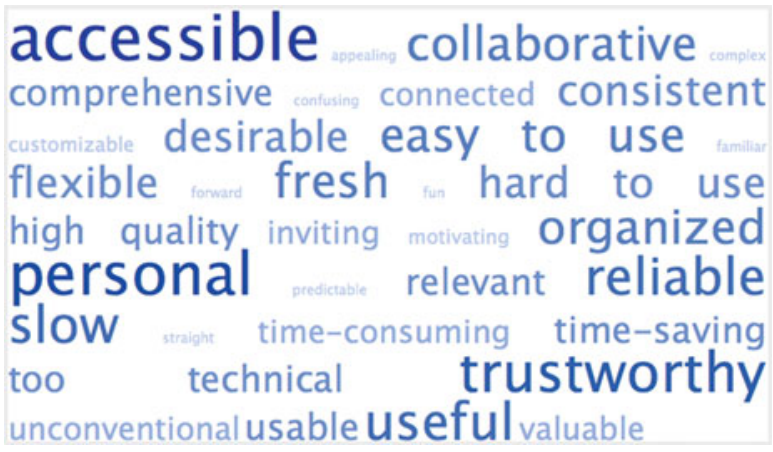




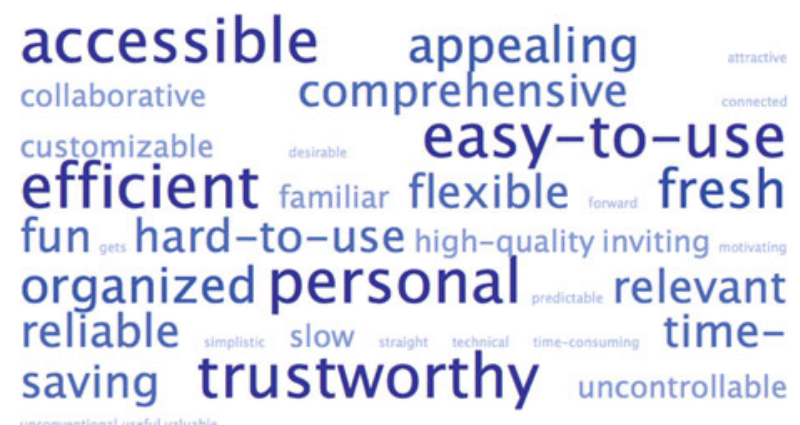

Fig. 5 A word cloud based on frequency of selected adjectives in 2012
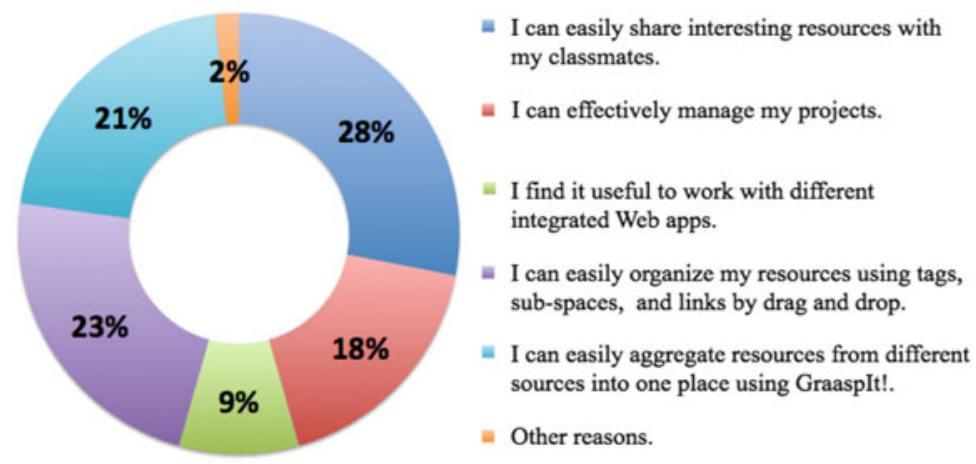

Fig. 6 Usefulness of the Graasp platform for teamwork

\section{Science 2.0 Literacy in Doctoral Studies}

Despite the fact that more and more European universities are putting together doctoral courses or programs, most of the learning activities for Ph.D. students are self-directed. As a consequence, doctoral students are really eager to develop their skills to conduct research and learn from their peers. Acknowledging this need, the Federation of the French-speaking Swiss universities $\left(\right.$ CUSO $^{9}$ ), which is offering inter-institutional continuing education programs, has decided to offer a soft skill workshop series co-organized by the University of Fribourg, the University of Geneva, and the EPFL to doctoral students of any discipline.

Three of these 2-day workshops were organized in 2011 and 2012. The first one held in Geneva was described in (Bogdanov et al. 2012). The second and third one held in Fribourg and in Lausanne, respectively, are discussed here.

\footnotetext{
${ }^{9}$ http://www.cuso.ch
} 
There were three objectives for the introduction of a PLE platform to support these workshops. First of all, it helped the educators belonging to the organizing institutions to collect and share their presentation material in advance and makes it available to the participants for preparation purpose prior the face-to-face sessions. This is a typical case when an open PLE platform is required as local institutional platforms cannot be used due to access restrictions for external people. Second, the PLE platform was exploited during the sessions by the participants to discuss and share their own resources and to practice their IT skills. Third, the participants were encouraged to continue to interact using the PLE platform after the events as an emerging community of practice.

The main topics covered during the workshops were the search and exploitation of digital resources (especially scientific references), digital intellectual property rights, as well as Science 2.0 practices using PLE platforms and other Web 2.0 tools.

In the part dedicated to PLE, Graasp was quickly introduced. A 30-min activity was then organized during which the participants had to build a personal space to collect references and discuss the state-of-the-art of their Ph.D. thesis with peers and with their supervisor. The participants created the spaces they deemed appropriate, invited selected people with the relevant roles, started to populate the spaces with chosen resources, and initiated discussions. This activity gave them the opportunity to discover the features of the Graasp PLE platform and experience with the benefits of contextual resource aggregation and discussion for a specific purpose.

The evaluation carried out at the end of the workshops was quite general and covered all the topics and the platforms presented during the 2-day events. One of the clear and obvious findings of the evaluation was that the students were overloaded with new tools. Hence, these tools need to provide a very high added value and have the potential to be exploited for the all duration of their Ph.D. studies for convincing Ph.D. candidates to invest time to master and exploit them. The main added value that was elicited for Graasp was its ability to aggregate resources from different sources in dedicated spaces; the resources being either Web bookmarks with previews or online documents. The other features were too numerous for the participants to really discover and benefit from them. Hence, we can conclude that in this case, the PLE platform was more useful for the educators to prepare, collect, and disseminate the teaching material in an agile and effective way, than for the participants. As a matter of fact, this is a general outcome of the ROLE project to highlight that sharing and repurposing of teaching materials among teachers, which are indeed self-directed learners, is an essential need which is effectively fulfilled with PLE platforms.

A side outcome that was expected from this workshop series was that, taking into account that in Switzerland all doctoral candidates also act as teaching assistants, the participants would disseminate their best IT practices and preferred PLE platforms in their teaching activities with undergraduate and master students. Whether this goal was achieved has not been evaluated. 


\section{Conclusions and Perspectives}

The main purpose of PLE platforms is to bring more flexibility for organizations, teachers, and students in the way they aggregate and exploit online resources and services, while relying on peers and experts outside the formal class settings around which the traditional curricula are still organized. As a consequence, the application of the underlying PLE paradigms goes beyond the cases described in the previous sections. In fact, interesting new application domains have emerged recently and are described below. First of all, the concept of shared spaces integrating applications happens to fulfill to need of inquiry-learning education at school using online labs. This case is described in section "Inquiry Learning Space for STEM Education at School Using Online Labs." As the informal aggregation of resources from various sources and shared with various people is part of the definition of agile knowledge management, large NGOs are becoming interested in the PLE platform paradigm. The NGOs' requirements and how they can contribute to the enrichment of PLE platforms are described in section "Supporting NGOs." Last but not least, the current trend in delivering Massive Open Online Courses (MOOCs) using revamped LMS platforms brings back the old question of finding the right balance between teaching and learning in higher education. While the mainstream MOOCs platforms like Coursera or EdX emphasis paced video content delivery, the PLE platforms can enable connectivist MOOCs to be implemented by enabling teachers or students to assemble and control the exploitation of openly available learning resources. This case is discussed in section "Supporting Connectivist MOOCs."

\section{Inquiry-Learning Space for STEM Education at School Using Online Labs}

The European Commission is funding for 4 years (2012-2016) a large-scale research project called Go-Lab aiming at promoting Science, Technology, Engineering, and Mathematics (STEM) education at school using online labs (Gillet et al. 2013). The solutions required to achieve this goal are trifold. First, Go-Lab has to strengthen and support communities of STEM teachers. Second, Go-Lab has to provide students with inquiry-learning spaces enabling the exploitation of online labs with proper scaffolds. Third, the online labs should be accessible through open Web apps facilitating their aggregation and repurposing by the teachers themselves.

The ability of the PLE platform presented in section "Prototypal Implementation" to support online communities, to create structured spaces, and to aggregate Web apps fully fulfills the Go-Lab requirements. In Go-Lab, Graasp is exploited by teachers to create inquiry-learning spaces in which they can organized all the resources necessary for the students to carry out the five typical phases of inquiry learning, i.e., orientation, conceptualization, investigation, conclusion, and discussion (Fig. 7). 


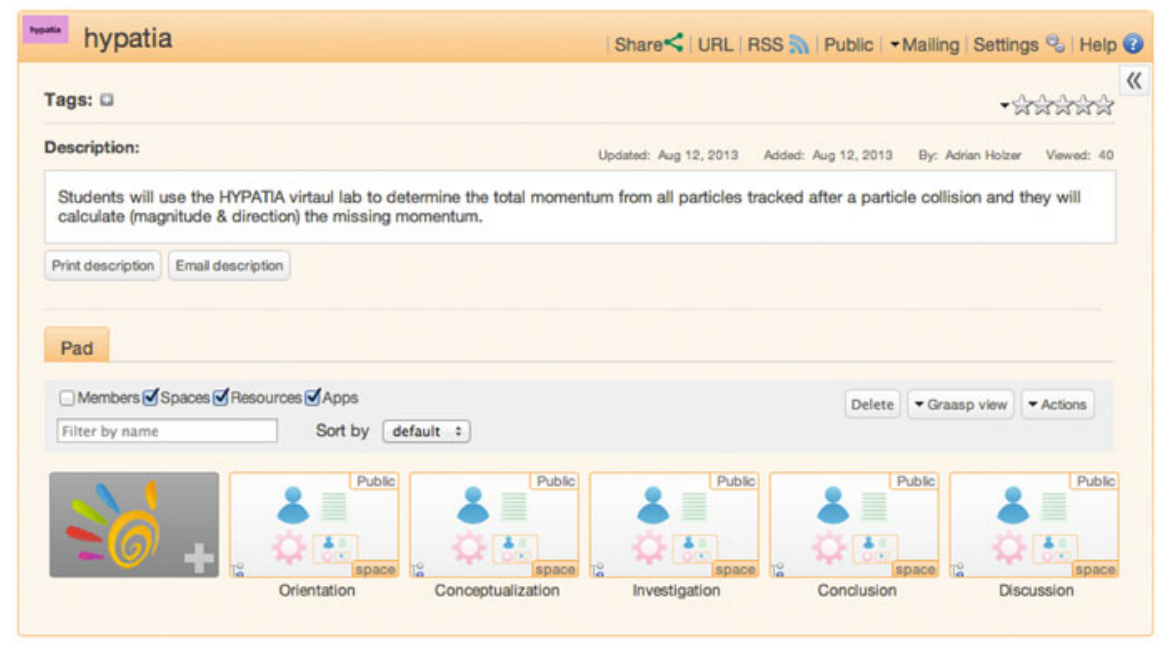

Fig. 7 The Graasp PLE platform exploited by teachers to create, share, and repurpose inquirylearning spaces dedicated to STEM education (in this case to exploit the Hypatia tool provided by CERN to study to conservation of momentum in collisions of particles)

The lower or higher secondary school students typically carrying out inquirylearning activities having to concentrate on exploiting the online labs, obviously do not interact with the PLE platform. However, the export feature of Graasp enables the creation of a standalone version of the constructed PLE as an independent Web app. The teacher can create this app once the PLE is ready by clicking on the share button. A secret URL that can be shared with the students is then generated. It provides access to a simple Web page in which the inquiry-learning phases are represented by tabs under which the resources (including the labs) selected by the teachers and the instructions given in the embedded spaces' wiki are accessible (Fig. 8).

This example shows how a PLE platform can be exploited by teachers to construct advanced educational resources, which can not only be presented in a simple form to students, but also shared and repurposed by other teachers for their own classroom activities. 
Students will use the HYPATIA virtaul lab to determine the total momentum from all particles tracked after a particle collision and they will calculate (magnitude \& direction) the missing momentum.

Orientation Conceptualization Investigation Conclusion Discussion

Here you can practice with the laboratory to find out how to operate it and what you can do with it. This will be useful to plan your experiment(s). Once you select a track from the table at the bottom you can see its track in the detector from two different points of view. The selected track appears in pink. In the table below you may see its momentun and its angle for both planes.

Based on what you see in the detector, can you tell what kind of particles they are?

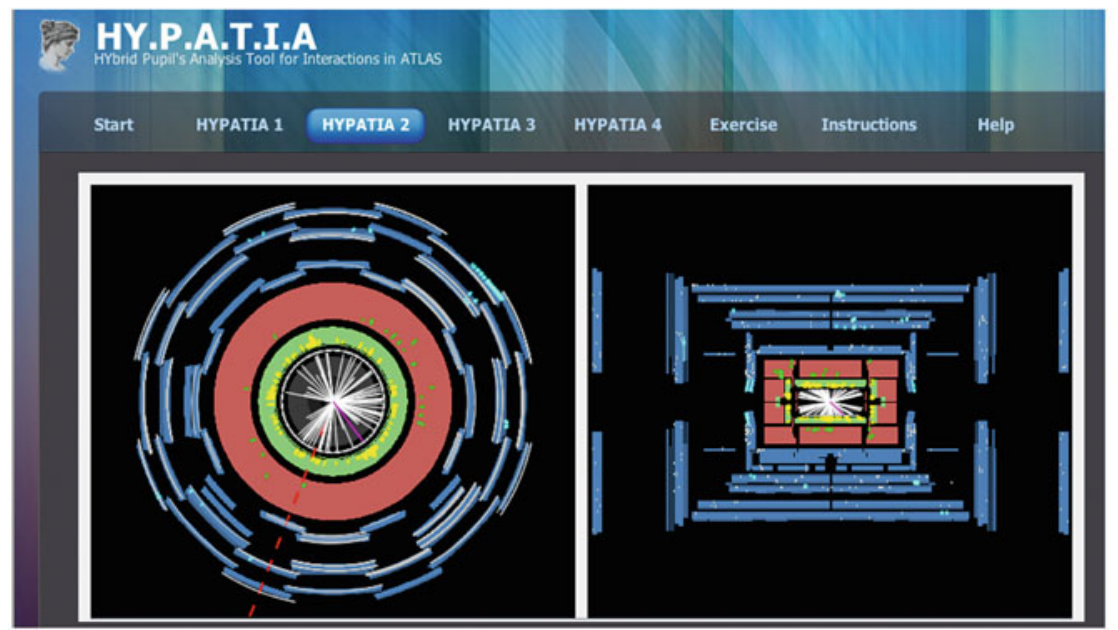

Fig. 8 The simple Web page corresponding to the inquiry-learning space constructed by a teacher (Fig. 7) with embedded Web applications for inquiry learning at school

\section{Supporting NGOs}

The PLE and online contextual space features introduced in the previous sections have attracted the interest of global institutions, organizations, and enterprises, and especially nongovernmental organizations (NGOs), not for personal learning, but for agile knowledge management. These knowledge-oriented organizations are operating at a worldwide scale with distributed entities loosely integrated and relying on local hierarchical structures (Gillet and Bogdanov 2013). NGOs have also fast staff turnover and strong digital asset dependency, which require effective knowledge management solutions. The ability to create contextual spaces managed in an easy and agile way by freelance experts in the field or in operation is hence very attractive to such organizations. Their main additional requirements compared to the defined PLE platforms are:

- Being able to integrate aggregation and interaction spaces in matrix structures (a space corresponding to a given project like Digging a Well in Ouagadougou should be simultaneously located in a geographical area (Africa as an example), 
in an activity domain (like water management), and a hierarchical department (like operation).

- Managing access rights by roles, i.e., the owner of a space should be identified as Project X Leader rather than John Smith (or both) to enable an easy transfer of duties and resources to someone else when required.

- Enabling fine identity management such as fusion of user profiles when people contribute to spaces with various credential (such as a general gmail account or social media platform OpenID) for consolidation purpose.

- Facilitating changes in access rights, i.e., having no distinction between the intranet and the extranet or the internal and external cloud infrastructures (as an example, when public documents are drafted and then made publically available, such feature eases the diffusion process).

- Guarantying the secrecy of some resources as NGOs are often dealing with content which can be politically sensitive. As a consequence, the physical and geographical location of the cloud resources should be fully defined and controlled.

- Automating tagging of contributed content to ease search and recommendation without diverting contributors from their main tasks.

- Enabling proper licensing schemes (such as Creative Commons) for digital content so that public resources can only be used or shared under specific conditions defined by the owner.

Such requirements are also very useful in the context of personal learning in which people often combine digital identities (e.g., when they move from one educational institution to another), where privacy issues are also critical (especially when dealing with young students), and where agile role management makes collaborative learning more effective. This section shows the interplay between personal learning and knowledge management in terms of supporting platforms and elicited requirements. In the future, design and validation between these two domains should be conducted more closely for cross-fertilization.

\section{Supporting Connectivist MOOCs}

PLE platforms have recently attracted interest from educators looking for agile solutions to develop connectivist MOOCs (Connectivist MOOCs 2013), referred as cMOOCs. Compare to the mainstream MOOC platforms like Coursera or EdX which are basically LMS open to external students, PLE platforms offer built-in social media features to boost opportunistic interaction and informal exchanges between students. These platforms can also help teachers and learners to aggregate their own MOOCs from resources freely available in the Cloud under Creative Commons licenses.

The possibility to add Web apps in PLE platforms is enabling an easy adaption for their exploitation to support connectivist courses, and especially cMOOCs. Kop 
et al. (Kop et al. 2011) highlighted that a connectivist course is based on four major types of activities, i.e., Aggregation, Remixing, Repurposing, and Sharing, which are the typical actions supported by PLE platforms. What is however missing in PLE platforms compare to MOOC platforms is the support for the formal activities. Especially, features to support coaching and assessment are missing, as well as features to support the timing and the structuring of the activities, including the associated content delivery and task assignment. Such features can easily be added in PLE platforms simply by integrating dedicated Web apps. This possible agile extension of the platforms through apps also enables the implementation of solutions to support a broad range of MOOC models, from the most formal to the fully connectivist ones.

Requirement elicitation for cMOOC support in PLE platforms carry out with members of the RESCIF ${ }^{10}$ Network of Excellence in Engineering Sciences of the French-speaking countries have highlighted that the following features are especially required:

- Peer evaluation support.

- Creation of quizzes, collection of the answers and analysis.

- Team building and competence bartering support.

- Formalization of time-based and topic-based structures through spaces (timing and navigation) using tables of content, syllabuses or calendars for navigation and exploration.

- Support of additional metadata through internal tags (automatically identified or inherited from domain ontologies) to ease search and recommendation.

- Customization of the portal spaces hosting cMOOCs with graphical templates enforcing branding or group identity building.

- Management of multilingual resources (Wikipedia model) supporting a given activity to broaden the audience and the sharing opportunities with developing and emerging countries.

- Tagging and subtitling of video sequences.

- Online recording and editing of video sequences.

- Integration of e-textbook standard documents (epub3).

These features can however be provided as specialized Web apps. Once integrated in a space dedicated to a cMOOC, these apps are accessible to all members, can be personalized and can store or retrieve information related and resources belonging to this space.

When relying on a PLE platform, a cMOOC implementation facilitates the co-production and co-exploitation of content between different teachers which can provide only materials directly related to their core expertise and rely on colleagues from other institutions for additional OER. Such an approach implemented using a mainstream platform would require challenging intellectual property right negotiations and bilateral conventions for exploitation. As such, the

${ }^{10}$ http://www.rescif.net/en/rescif 
PLE platform not only enables to flip the classrooms (by freeing classroom time for personal interaction), but also to flip the institutions (by redefining the educational mission towards collaborative high-quality content edition and accreditation).

\section{Final Words}

PLE as considered in higher education correspond simultaneously to a paradigm change in the ways the information is shared and consumed, as well as a paradigm change in the supporting technical ecosystem. Recognizing and acknowledging the large variety of practices and platforms for both formal and informal activities carried out by teachers and students is already an important institutional change. Providing support in developing the necessary IT literacy of higher education stakeholders and even providing alternative PLE platforms helping them to increase their effectiveness in exploiting knowledge artifacts and exchanging competences are the next level of the ongoing academic revolution. Contributions to support this change have been formalized and illustrated in this chapter.

Acknowledgments This work was partially funded by the European Union in the context of the ROLE (Grant Agreement no. 231396) and Go-Lab (Grant Agreement no. 317601) projects under the Information and Communication Technologies (ICT) theme of the 7th Framework Programme for R\&D (FP7), as well as the Personal Learning Environment (Phase 3) project of the Swiss AAA/SWITCH program and the Learning Infrastructure project of the Swiss CUS Programme P-2 on Scientific Information: Access, Processing, and Storage.

Open Access This chapter is distributed under the terms of the Creative Commons Attribution Noncommercial License, which permits any noncommercial use, distribution, and reproduction in any medium, provided the original author(s) and source are credited.

\section{References}

Benedek J, Miner T. Measuring desirability: new methods for evaluating desirability in a usability lab setting. Redmond: Microsoft Corporation; 2002.

Bogdanov E, Salzmann C, Gillet D (2011) Contextual spaces with functional skins as open social extension. In: Fourth International conferences on advances in computer-human interactions (ACHI), Feb 23-28, Guadeloupe, France.

Bogdanov E, Limpens F, Li N, El Helou S, Salzmann C, Gillet D (2012) A social media platform in higher education. In: Global engineering education conference (EDUCON), Apr 17-20, Marrakesh, Morocco.

Charlier B, Henri F, Peraya D, Gillet D (2010) From personal environment to Personal Learning Environment. In: Fifth European Conference on Technology Enhanced Learning (EC-TEL), Workshop on Mash-Up Personal Learning Environments (MUPPLE), Sept 28-Oct 1, Barcelona, Spain.

Connectivist MOOCs. 2013. http://www.connectivistmoocs.org. Accessed 27 June 2013. 
El Helou S, Gillet D, Salzmann C, Rekik Y. Social software for sustaining interaction, collaboration and learning in communities of practice. In: Karacapilidis N, editor. Solutions and innovations in web-based technologies for augmented learning: improved platforms, tools, and applications, Advances in web-based learning (AWBL) book series. Hershey: IGI Global; 2009. p. 300-16.

El Helou S, Li N, Gillet D. The 3A interaction model: towards bridging the gap between formal and informal learning. In: Third International conference on advances in computer-human interactions (ACHI), Feb 10-16, 2010, St. Maarten, Netherlands Antilles.

Gillet D. Tackling engineering education research challenges: Web 2.0 social software for personal learning. Int J Eng Educ. 2010;26(5):1134-43.

Gillet D. Personal learning environments as enablers for connectivist MOOCs. In: 12th International conference on information technology based higher education and training (ITHET), Oct 10-12, 2013, Antalya, Turkey.

Gillet D, Bogdanov E. Cloud-savvy contextual spaces as agile personal learning environments or informal knowledge management solutions. In: 12th International conference on information technology based higher education and training (ITHET), Oct 10-12, 2013, Antalya, Turkey.

Gillet D, El Helou S, Yu CM, Salzmann C. Turning Web 2.0 Social software into versatile collaborative learning solutions. In: First International conference on advances in computerhuman interaction (ACHI), Feb 10-15, 2008, Sainte Luce, Martinique

Gillet D, Law E, Chatterjee A. Personal learning environments in a global higher engineering education Web 2.0 Realm. In: Global engineering education conference (EDUCON), Apr 1416, 2010, Madrid, Spain.

Gillet D, de Jong T, Sotirou S, Salzmann C. Personalised learning spaces and federated online labs for STEM education at school: supporting teacher communities and inquiry learning. In: 4th IEEE global engineering education conference (EDUCON), March 13-15, 2013, Berlin, Germany.

Greenhow C, Robelia B. Informal learning and identity formation in online social networks. Learn Media Technol. 2009;34(2):119-40.

Kop R, Fournier H, Mak SFJ. A pedagogy of abundance or a pedagogy to support human beings? Participant support on massive open online courses. Int Rev Res Open Dist Learn. 2011;12(7).

Li N, El Helou S, Gillet D. Using social media for collaborative learning in higher education: A case study. In: Fifth International conference on advances in computer-human interactions (ACHI), Jan 30-Feb 4, 2012, Valencia, Spain.

Vassileva J. Toward social learning environments. IEEE Trans Learn Technol. 2008;1(4): 199-214.

Wild F, Mödritscher F, Sigurdarson S. Designing for change: mash-up personal learning environments. 2008. eLearning Papers 9. 